\title{
Dietary diversity, animal source food consumption and linear growth among children aged 1-5 years in Bandung, Indonesia: a longitudinal observational study
}

\author{
Siti Muslimatun ${ }^{1,2}$ and Luh Ade Ari Wiradnyani ${ }^{1 *}$ \\ ${ }^{1}$ Southeast Asian Ministers of Education Organization Regional Center for Food and Nutrition/SEAMEO RECFON, Universitas \\ Indonesia, Jakarta 10430, Indonesia \\ ${ }^{2}$ Food Science Department, Indonesia International Institute for Life Sciences, Jakarta 13210, Indonesia
}

(Submitted 13 October 2014 - Final revision received 12 November 2015 - Accepted 16 November 2015 - First published online 28 January 2016)

\section{Abstract}

Dietary diversity involves adequate intake of macronutrient and micronutrient. The inclusion of animal source foods (ASF) in the diet helps prevent multiple nutrient deficiencies and any resultant, linear growth retardation. The objective of the current study was to assess the relationship between dietary diversity, ASF consumption and height-for-age $z$-score (HAZ) among children aged 12-59 months old across a 1-year observation. This longitudinal observational study without controls was conducted among four age groups: 12-23 months ( $n$ 57), 24-35 months ( $n$ 56), 36-47 months ( $n$ 58) and 48-59 months ( $n$ 56). Anthropometry and dietary intake were measured during each of four visits at 16-20-week intervals. The general characteristics and other observations were only collected at baseline and endline. During the year-long study period, approximately $27 \%$ of the children ate a diverse diet (consumed $\geq 6$ out of 9 food groups) according to $\geq 3$ visits. ASF consumption was high, particularly for eggs, poultry, processed meats and liquid milk. Yet, micronutrient intake inadequacy, especially of $\mathrm{Zn}, \mathrm{Ca}$, Fe and vitamin $\mathrm{A}$, was highly prevalent. A multivariate regression analysis showed that the consumption of a diverse diet and ASF was not significantly associated with the HAZ at endline, after controlling for demographic characteristics and the baseline HAZ. The consumption of a diverse diet was significantly associated with Ca intake adequacy. Moreover, ASF consumption was significantly associated with adequate intake of protein and micronutrients, particularly vitamin A, $\mathrm{Ca}$ and $\mathrm{Zn}$. Thus, the recommendation is to continue and strengthen the promotion of consuming a diverse diet that includes ASF in supporting the linear growth of young children.

\section{Key words: Dietary diversity: Animal source foods: Children: Linear growth: Indonesia}

Linear growth faltering is a major problem among children in Indonesia, as shown by the high prevalence of stunting. The national survey in 2013 showed that the growth of $37.2 \%$ of children $<5$ years old was stunted. This figure is not significantly different from the results of the 2007 national survey ${ }^{(1)}$. The consequences of stunting include increased child mortality ${ }^{(2)}$, prolonged illness, delayed psychomotor development and negative outcomes in adulthood ${ }^{(3)}$.

The inadequate intake of a quality diet rich in energy, protein and micronutrients is among the main contributing factors for stunting $^{(4)}$, and it is common in developing countries such as Indonesia. Recent studies have shown that among Indonesian children aged 2-5 years the proportions of inadequate intake of energy and protein were 60.5 and $35.8 \%$, respectively. The proportions of inadequate intake of micronutrients such as $\mathrm{Ca}$, Fe, vitamin C and vitamin A were even higher (80.9, 83.5, 84.3 and $79 \cdot 1 \%$, respectively) ${ }^{(5)}$
Dietary diversity is one of the key elements of a quality diet, and it is thought to enhance the probability of the adequate intake of essential nutrients to promote good health. A more diverse diet is highly correlated with adequate energy and protein $^{(6)}$, micronutrients ${ }^{(7,8)}$, animal source food (ASF) protein intake and diet variety/balance ${ }^{(9)}$.

ASF are of a better quality than plant source foods for supplying micronutrients and protein, because the former contain more of such elements with better bioavailability ${ }^{(10)}$. The most important micronutrients contained in ASF are Fe, Zn, $\mathrm{Ca}$, riboflavin, vitamin $\mathrm{A}$ and vitamin $\mathrm{B}_{12}$. Hence, relatively small amounts of ASF can substantially increase nutrient adequacy $^{(11)}$. ASF consumption has been positively associated with better growth and mental development, less morbidity and anaemia, as well as higher immune function ${ }^{(12)}$. Among school children in Kenya, food interventions containing milk and meat had a positive effect on height gain ${ }^{(13)}$. Neumann et al. ${ }^{(14)}$ show

Abbreviations: ASF, animal source food; HAZ, height-for-age z score.

* Corresponding author: L. A. A. Wiradnyani, fax +62 21 3913933, email awiradnyani@gmail.org

Disclaimer: Publication of these papers was supported by unrestricted educational grants from PT Sarihusada Generasi Mahardhika and PT Nutricia Indonesia Sejahtera. The papers included in this supplement were invited by the Guest Editors and have undergone the standard journal formal review process. They may be cited. The Guest Editors declare that there are no conflicts of interest. 
that a child would need to consume $1 \cdot 7-2 \cdot 0 \mathrm{~kg}$ of maize and beans in a day to meet energy, $\mathrm{Fe}$ and $\mathrm{Zn}$ requirements. Similarly, children cannot meet daily Ca requirements if they rely solely on cereal-based diets.

In Indonesia, the practice of 'infant and young child feeding' among children aged 6-23 months showed that $54.2 \%$ consumed meat/fish/poultry, $48.3 \%$ consumed eggs and $8.8 \%$ consumed milk. In terms of dietary diversity, $58.2 \%$ of the children consumed $\geq 4$ food groups ${ }^{(15)}$.

The objective of the current research was to study the interactions of dietary diversity, ASF consumption and heightfor-age $z$ score (HAZ) by examining the relationship between dietary diversity and nutrient intake adequacy among children aged 12-59 months over the course of a year. This longitudinal observation, with four dietary assessments over the 1-year period, was expected to better capture children's typical dietary intake.

\section{Methods \\ Study design and area}

The current work was a longitudinal observational study without controls conducted in Bandung city, an urban area with a population of 2.4 million, around $120 \mathrm{~km}$ from Indonesia's capital, Jakarta. The period of observation was 1 year with four assessments. The longitudinal study design was selected to capture the dynamics of feeding and care practices among children.

\section{Subjects}

The subjects were apparently healthy male and female children aged 12-59 months. Children who had symptoms of chronic/ congenital diseases or disabilities, or who were twins or multiple births were not included in the study. During screening, we did not find any children who were severely malnourished (weightfor-height $z$-score $<-3.00 \mathrm{sD}$ ). To obtain a better picture of the full age range (12-59 months), the children were stratified according to age groups of 12-23, 24-35, 36-47 and 48-59 months.

\section{Sample size and sampling procedure}

To detect a difference of 1 year length/height increment of 6 (9.48 SD) cm, a $P$ value of 0.05 , a power of $80 \%$ and an anticipated dropout of $30 \%$, fifty-three subjects per age group were required ${ }^{(16)}$. The study included 220 children ( 55 children $\times 4$ age groups).

The children were selected from eleven out of thirty growth monitoring posts (Posyandu), with the lowest mean for the HAZ included in previous studies assessing the sensitivity and specificity of dietary diversity scores with micronutrient intake (L Marlina, unpublished results). Each Posyandu covered 50150 children under 5 years of age. The children from the eleven selected Posyandu were listed, and those meeting the inclusion criteria were grouped into their age strata. When the total number of children was more than that required within their age group, a simple random selection was used, with a goal of five children in each age group in every Posyandu.

\section{Data collection procedures}

Each subject underwent four assessments - at baseline, follow-up I, follow-up II and at endline - with intervals of 16-20 weeks between assessments. The interviews were conducted using structured, pre-tested questionnaires at each visit. Each interview took approximately $40 \mathrm{~min}$ for each mother/caregiver. The questionnaires for mothers/caregivers consisted of questions on household demographic data, socio-economic status, mothers/ caregivers' knowledge of health and nutrition, child care practices, child morbidity and the households' access to water and sanitation. The children's food intake was assessed using repeated 24-h recall of 2 non-consecutive days during each visit. Thus, within 1 year, there were 8 food recall $\mathrm{d}$ /child for those who fully participated. A set of food models was displayed to help mothers/ caregivers estimate portion sizes when recalling the amounts of all of the foods and beverages consumed by their children on the recall days, from when the children woke up in the morning until they went to sleep in the evening, including any night feedings. The types of foods and ingredients, the ways in which the foods were prepared and the brands of certain foods (especially milk, dairy products and manufactured snacks) were recorded. The interviews and dietary assessments were conducted by trained enumerators, who also performed the weight and height/length measurements at baseline and endline using standardised procedures and equipment ${ }^{(17)}$.

\section{Ethical considerations}

The researchers explained the study's purpose and procedures at enrolment. Only subjects who gave written informed consent were recruited. Assurance was given that participation was voluntary and that no negative consequences would result for those who decided not to participate in the study or for those who withdrew during the study period. The study protocol received ethical clearance from the Ethical Committee of the Faculty of Medicine, Universitas Indonesia.

\section{Data analysis}

The data from the questionnaires were entered in SPSS version 16.0, and those from the dietary assessment were entered and converted into energy and nutrient intake using the NutriSurvey software program (www.nutrisurvey.de) based on Indonesian Food Composition Tables.

The data analysis was conducted using IBM SPSS version 20.0. Where appropriate, the data were checked for normality of distribution using the Kolmogorov-Smirnov test of normality. One of the two 24-h dietary recalls during each visit was selected randomly to measure the dietary diversity, which was calculated based on the nine food groups according to the Guidelines for Measuring Household and Individual Dietary Diversity: ${ }^{(9)}$ (i) cereals/tubers/grains; (ii) meat, poultry, fish (flesh foods); (iii) milk and dairy products (excluding sweetened condensed milk); (iv) eggs; (v) nuts/legumes; (vi) vitamin A-rich fruits, vegetables and tubers; (vii) other fruits; (viii) other vegetables; and (ix) fats and oil. The dietary diversity was divided into 'diverse diet' (indicated by the consumption of $\geq 6$ out of the 9 food groups) and 
'less diverse diet' (indicated by the consumption of $<6$ out of the 9 food groups). Six food groups were used as the cut-off in this study based on a previous study conducted in an urban area of Mali ${ }^{(18)}$, which was corroborated by another study in Bandung City that set the optimal cut-off point for the number of food groups that could identify micronutrient intake inadequacy among children aged 23-59 months with high sensitivity and specificity at 5.5 (Marlina, unpublished results). Subsequently, ASF were further subdivided into flesh foods (fish/seafoods, red meat, chicken and processed foods) and milk/dairy (powdered and liquid milk).

The estimation for the proportion of children with energy and nutrient intake inadequacy was calculated at baseline and endline using the PC-Side program based on two repeated 24-h recalls. The Indonesian's RDA ${ }^{(19)}$ was used as the reference for nutrient adequacy. The estimated average intake (EAR) cut-off point method was applied to calculate vitamin $\mathrm{A}, \mathrm{Zn}$ and $\mathrm{Ca}$ inadequacies $^{(17,20)}$. This study used the conversion factors for calculating the EAR provided by the WHO/FAO in $2006^{(20)}$. As the EAR for energy and protein intake was not specified, this study used $77 \%$ of the RDA as the cut-off value to estimate the EAR, and in turn to calculate energy and protein intake inadequacies ${ }^{(17)}$. The cut-off for inadequacy was calculated based on each child's actual age at each visit. Nevertheless, among children aged 36-47 months, the baseline and endline used the same cut-off, even though the children were $\geq 48$ months old at endline and 'by reference' had different cut-offs. For Fe, the conversion factor for children aged $\leq 9$ years was not provided because of high variability and the skewed nature of the distribution of the requirement for $\mathrm{Fe}$ in this population sub-group. Hence, a full-probability method was recommended to estimate the prevalence of Fe inadequacy ${ }^{(20)}$. This study used $10 \%$ of Fe bioavailability ${ }^{(21)}$. Among breast-fed children, a medium amount of breastmilk consumption was used to calculate energy and nutrient intake ${ }^{(22)}$.

In the bivariate and multivariate analyses, the frequency of food group consumption, dietary diversity and energy and nutrient intake adequacy was categorised into two groups based on a 1-year observation period (derived from the four 24-h dietary recalls, one for each visit): 'less frequently consumed' and 'more frequently consumed' for each food type. The former indicated that the respective food group was consumed in $<3$ out of the four dietary recalls and the latter meant that it was consumed in $\geq 3$ out of the four dietary recalls. The dietary diversity was categorised as 'had diverse diet in $<3$ visits' when the subject consumed $\geq 6$ food groups in $<3$ out of the four dietary recalls, and as 'had diverse diet in $\geq 3$ visits' when the subject had consumed $\geq 6$ food groups in $\geq 3$ out of the four dietary recalls.

The energy and nutrient intake adequacy was categorised as 'had adequate intake in $\geq 3$ visits' when the adequacy was met in $\geq 3$ out of the four dietary recalls, and as 'had adequate intake in $<3$ visits' when the adequacy was only met in $<3$ out of the four dietary recalls. A different categorisation was used for $\mathrm{Zn}$ adequacy, that is, 'had adequate intake in $\geq 3$ visits' when the adequacy was met in $\geq 2$ out of the four dietary recalls, to accommodate the very low proportion of subjects with adequate $\mathrm{Zn}$ intake.

The bivariate analysis was performed to assess the association between the frequency of consumption of certain food groups and the dietary diversity category with energy intake adequacy and HAZ at endline. Subsequently, a multivariate linear regression analysis was used to understand the roles of food group consumption, dietary diversity and energy and nutrient intake adequacy in explaining the HAZ at endline, controlling for demographic characteristics and the HAZ at baseline. The regression test used a $<0.05$ level of significance. The household wealth index was constructed using a principle component analysis of the variable households' ownership of motorcycles, refrigerators and houses in addition to the type of drinking water source. The household wealth index was divided into tertiles.

\section{Results}

The study enrolled 227 children at baseline (56.4\% female and $43.6 \%$ male). By the end of the study, 210 (92.5\%) children had undergone the endline assessment, and 203 (89.4\%) had undergone all four assessments. Any incomplete assessments were mainly the result of the children moving to other places or visiting relatives at the time of data collection. The proportions of loss to follow-up were $3.5 \%$ at follow-up I, $6.6 \%$ at follow-up II and $7.0 \%$ at endline.

\section{Baseline characteristics}

There were no significant differences in the baseline characteristics (age, weight, length/height and nutritional status) between children who missed one or more assessments and those who attended all of the assessments (data not shown).

The overall prevalence of stunting was $34.4 \%$, with the highest being among children aged 12-23 months and the lowest among children aged 24-35 months. The prevalence of wasting was highest among children aged 12-23 months and lowest among children aged 48-59 months (Table 1), but the differences were not significant. The length increment between baseline and endline was $7 \cdot 1$ ( $\mathrm{SD} 1.6) \mathrm{cm}$ ( $n$ 211), with the highest $(8.6(\mathrm{sD} 1.9) \mathrm{cm})$ among children aged $12-23$ months and the lowest $(5.8(\mathrm{sD} 1.0) \mathrm{cm})$ among children aged $48-59$ months. The length increment among children aged 12-23 months was significantly higher $(P<0.05)$ than the other age groups. The proportion of mothers with $\geq 12$ years of schooling was $42.7 \%$, and only about one-third of the households had a regular monthly income (34.8\%). Moreover, only $33.9 \%$ of the households resided in their own house. Access to a private toilet facility was available in $73.1 \%$ of the households.

\section{Breast-feeding and introduction to complementary foods}

All of the children in the study, except one, were ever breast-fed. Among the children aged 12-23 months, 75\% were breast-fed at baseline and $13.5 \%$ remained breast-fed at endline. Among the children who were no longer breast-fed, the majority were weaned in their 2nd year of life. Four in every ten mothers gave prelacteal foods/fluids to their children within the 1st week after birth. Complementary foods were introduced when the children were 6 months old (43.2\%), younger than 6 months (41.9\%) or older than 6 months $(14.9 \%)$. 
Table 1. Characteristics of the subjects at baseline

(Mean values and standard deviations)

\begin{tabular}{|c|c|c|c|c|c|c|c|c|c|c|}
\hline \multirow[b]{2}{*}{ Characteristics } & \multicolumn{2}{|c|}{$\begin{array}{c}\text { 12-23 months } \\
(n 57)\end{array}$} & \multicolumn{2}{|c|}{$\begin{array}{c}\text { 24-35 months } \\
(n 56)\end{array}$} & \multicolumn{2}{|c|}{$\begin{array}{l}\text { 36-47 months } \\
\text { ( } n \text { 58) }\end{array}$} & \multicolumn{2}{|c|}{$\begin{array}{c}\text { 48-59 months } \\
(n 56)\end{array}$} & \multicolumn{2}{|c|}{ All (n 227) } \\
\hline & Mean & SD & Mean & SD & Mean & SD & Mean & SD & Mean & SD \\
\hline Female:male $(n)$ & \multicolumn{2}{|c|}{$29: 28$} & \multicolumn{2}{|c|}{$28: 28$} & \multicolumn{2}{|c|}{$35: 23$} & \multicolumn{2}{|c|}{$36: 20$} & \multicolumn{2}{|c|}{ 128:99 } \\
\hline Age (months) & $17 \cdot 5$ & $3 \cdot 2$ & 30.4 & 3.4 & $41 \cdot 7$ & 3.4 & $54 \cdot 3$ & 3.5 & 35.9 & $14 \cdot 0$ \\
\hline Body weight (kg) & $9 \cdot 4$ & $1 \cdot 2$ & $11 \cdot 8$ & 1.8 & $13 \cdot 1$ & $2 \cdot 0$ & 14.9 & 1.8 & $12 \cdot 3$ & $2 \cdot 6$ \\
\hline Body height/length $(\mathrm{cm})$ & $76 \cdot 1$ & $3 \cdot 8$ & $86 \cdot 7$ & $4 \cdot 1$ & 92.4 & 4.9 & $99 \cdot 3$ & $4 \cdot 1$ & $88 \cdot 6$ & 9.5 \\
\hline Suffered from either runny nose, coughing or fever (\%) & \multicolumn{2}{|c|}{$26 \cdot 3$} & \multicolumn{2}{|c|}{$25 \cdot 0$} & \multicolumn{2}{|c|}{22.4} & \multicolumn{2}{|c|}{21.4} & \multicolumn{2}{|c|}{23.8} \\
\hline $\mathrm{HAZ}$ & -1.69 & 1.09 & -1.39 & 0.87 & -1.69 & 0.96 & -1.61 & 0.82 & -1.59 & 0.94 \\
\hline WAZ & -0.93 & 1.05 & -0.92 & 1.06 & $-1 \cdot 18$ & 1.00 & $-1 \cdot 13$ & 0.89 & -1.04 & 1.00 \\
\hline WHZ & -0.17 & $1 \cdot 21$ & -0.24 & $1 \cdot 10$ & -0.29 & 0.97 & -0.23 & 0.90 & -0.23 & $1 . .04$ \\
\hline BMIZ & $0 \cdot 13$ & $1 \cdot 3$ & -0.08 & $1 \cdot 11$ & $-0 \cdot 13$ & 0.93 & -0.16 & 0.86 & -0.06 & 1.05 \\
\hline Stunting (\%) & \multicolumn{2}{|c|}{$45 \cdot 6$} & \multicolumn{2}{|c|}{$25 \cdot 0$} & \multicolumn{2}{|c|}{34.5} & \multicolumn{2}{|c|}{$32 \cdot 1$} & \multicolumn{2}{|c|}{34.4} \\
\hline Underweight (\%) & \multicolumn{2}{|c|}{$14 \cdot 0$} & \multicolumn{2}{|c|}{$16 \cdot 1$} & \multicolumn{2}{|c|}{$17 \cdot 2$} & \multicolumn{2}{|c|}{$17 \cdot 9$} & \multicolumn{2}{|c|}{$16 \cdot 3$} \\
\hline Wasting $(\%)$ & \multicolumn{2}{|c|}{$8 \cdot 8$} & \multicolumn{2}{|c|}{5.4} & \multicolumn{2}{|c|}{$3 \cdot 4$} & \multicolumn{2}{|c|}{$1 \cdot 8$} & \multicolumn{2}{|c|}{$4 \cdot 8$} \\
\hline Overweight (\%) & \multicolumn{2}{|c|}{$5 \cdot 3$} & \multicolumn{2}{|c|}{3.6} & \multicolumn{2}{|c|}{3.4} & ( & & & 1 \\
\hline Mothers with $\geq 12$ years education (\%) & & & & & & & & & & \\
\hline Mothers were housewife (\%) & & & & & & & & & & \\
\hline Household with access to private toilet (\%) & & & & & & & & & & \\
\hline Household had irregular income (\%) & & & & & & & & & & \\
\hline
\end{tabular}

HAZ, height-for-age $z$ score; WAZ, weight-for-age $z$ score; WHZ, weight-for-height $z$ score; BMIZ, BMI $z$ score.

Table 2. Consumption of diverse diet and dietary diversity score across visits (\%)

\begin{tabular}{|c|c|c|c|c|}
\hline & Baseline ( $n$ 227) & Follow-up I (n 219) & Follow-up II (n 211) & Endline ( $n$ 210) \\
\hline \multicolumn{5}{|l|}{ Name of food groups } \\
\hline Cereals and tubers & $99 \cdot 6$ & 100 & 100 & 100 \\
\hline Flesh foods (meat, poultry, fish, processed meat/poultry)* & $76 \cdot 7$ & 84.5 & 81.4 & $88 \cdot 1$ \\
\hline Milk and dairy product* & $65 \cdot 6$ & $65 \cdot 6$ & $67 \cdot 0$ & $79 \cdot 0$ \\
\hline Eggs & $58 \cdot 6$ & 64.4 & $61 \cdot 0$ & 61.9 \\
\hline Nuts/legumes & $40 \cdot 5$ & $47 \cdot 0$ & $46 \cdot 2$ & $45 \cdot 7$ \\
\hline Vitamin A-rich fruits, vegetables, tubers* & 41.9 & $43 \cdot 8$ & $43 \cdot 8$ & $31 \cdot 0$ \\
\hline Other fruits & $33 \cdot 5$ & $36 \cdot 5$ & $33 \cdot 8$ & $28 \cdot 1$ \\
\hline Other vegetables & $21 \cdot 1$ & $22 \cdot 8$ & 21.9 & $18 \cdot 1$ \\
\hline Fats and oil & 91.6 & $96 \cdot 3$ & $94 \cdot 3$ & $94 \cdot 3$ \\
\hline \multicolumn{5}{|l|}{ Number of food groups } \\
\hline$<3$ groups & $4 \cdot 0$ & $3 \cdot 2$ & 1.9 & 0.5 \\
\hline 3 groups & $8 \cdot 4$ & $5 \cdot 0$ & $7 \cdot 1$ & $5 \cdot 7$ \\
\hline 4 groups & $19 \cdot 8$ & $14 \cdot 6$ & $21 \cdot 0$ & $19 \cdot 0$ \\
\hline 5 groups & $29 \cdot 1$ & $25 \cdot 1$ & $24 \cdot 3$ & $32 \cdot 2$ \\
\hline 6 groups & $17 \cdot 6$ & $25 \cdot 1$ & $25 \cdot 7$ & $25 \cdot 1$ \\
\hline 7 groups & $10 \cdot 6$ & $17 \cdot 4$ & $12 \cdot 9$ & $11 \cdot 8$ \\
\hline$>7$ groups & $10 \cdot 6$ & $9 \cdot 6$ & $7 \cdot 1$ & $5 \cdot 7$ \\
\hline Consumed $\geq 6$ food groups & $38 \cdot 5$ & $51 \cdot 8$ & $45 \cdot 7$ & $42 \cdot 4$ \\
\hline
\end{tabular}

${ }^{*} P<0.05\left(\chi^{2}\right.$ test $)$

\section{Dietary diversity}

Table 2 presents the dietary diversity across the visits. Cereal/tubers and fats/oil were consumed by almost all of the children across all of the visits. Eggs were more commonly consumed than nuts/ legumes. Nevertheless, the consumption of these two food groups showed similar patterns: that is, it slightly increased from baseline to the next 4 months (follow-up I), and it did not change much afterwards. The consumption of flesh foods, milk and dairy products and vitamin A-rich fruits/vegetables was significantly different across visits. Although the consumption of flesh foods and milk and dairy products slightly increased across visits, the consumption of vitamin A-rich fruits and vegetables unexpectedly decreased.

With respect to the number of food groups, there was no significant difference in the number of food groups consumed across visits. About $50 \%$ of the children consumed 5-6 food groups in a day, and less than half of the children had good food variety (consumed $\geq 6$ food groups). The proportion of the children who had diverse diets in $\geq 3$ visits was $27 \cdot 2 \%$. The dietary diversity was not significantly different across visits or age groups (data not shown).

\section{Animal source food consumption}

Among the ASF, eggs were most commonly consumed, and their consumption was consistently high across visits (Table 3 ). Within the flesh food group, chicken and processed meats (such as sausage, meatballs and chicken nuggets) were most commonly consumed by the children across visits. Fish and seafood were only consumed by approximately $13 \%$ of the children, whereas red 
Table 3. Consumption of animal source foods across visits (\%)

\begin{tabular}{|c|c|c|c|c|}
\hline Type of animal source foods & Baseline (n 227) & Follow-up I (n 219) & Follow-up II (n 211) & Endline ( $n$ 210) \\
\hline Eggs & $58 \cdot 6$ & $64 \cdot 4$ & $61 \cdot 0$ & $61 \cdot 9$ \\
\hline Liquid milk & $32 \cdot 3$ & $33 \cdot 3$ & $34 \cdot 8$ & 44.5 \\
\hline Powder milk & 31.9 & $32 \cdot 0$ & $35 \cdot 7$ & $20 \cdot 4$ \\
\hline Other dairy products & $8 \cdot 3$ & $9 \cdot 2$ & $15 \cdot 2$ & 11.6 \\
\hline Fish and seafoods & $13 \cdot 7$ & $13 \cdot 7$ & $11 \cdot 1$ & $13 \cdot 2$ \\
\hline Chicken & $39 \cdot 2$ & 42.9 & 31.0 & $49 \cdot 3$ \\
\hline Processed meat & 48.9 & 52.5 & $50 \cdot 0$ & $44 \cdot 1$ \\
\hline Red meat & 2.6 & 1.8 & 11.9 & 9.8 \\
\hline Organ meat & 3.0 & $7 \cdot 3$ & 3.8 & $7 \cdot 8$ \\
\hline
\end{tabular}

Table 4. Energy and nutrient inadequacy at baseline and endline by age group (\%) $(20,21,23)$ *

\begin{tabular}{|c|c|c|c|c|c|c|c|c|c|c|c|}
\hline \multirow[b]{2}{*}{ No } & \multirow[b]{2}{*}{ Nutrients } & \multicolumn{2}{|c|}{$12-23$ months } & \multicolumn{2}{|c|}{ 24-35 months } & \multicolumn{2}{|c|}{ 36-47 months } & \multicolumn{2}{|c|}{ 48-59 months } & \multicolumn{2}{|c|}{ All } \\
\hline & & $\mathrm{BL}(n 57)$ & $\mathrm{EL}(n$ 49) & $\mathrm{BL}(n 56)$ & $\mathrm{EL}(n 50)$ & $\mathrm{BL}(n 57)$ & $\mathrm{EL}(n 50)$ & $\mathrm{BL}(n 56)$ & $\mathrm{EL}(n 51)$ & $\mathrm{BL}(n 226)$ & $\mathrm{EL}(n 200)$ \\
\hline 1 & Energy† & $7 \cdot 3$ & $2 \cdot 2$ & $6 \cdot 2$ & $2 \cdot 5$ & 1.4 & $5 \cdot 0$ & $49 \cdot 3$ & $37 \cdot 1$ & $15 \cdot 9$ & 11.9 \\
\hline 2 & Protein $\ddagger$ & $19 \cdot 1$ & 0.5 & 1.6 & $2 \cdot 0$ & $1 \cdot 1$ & 0.74 & 32.9 & $10 \cdot 6$ & $13 \cdot 6$ & 3.5 \\
\hline 3 & Vitamin A§ & $2 \cdot 3$ & $30 \cdot 9$ & $19 \cdot 1$ & $30 \cdot 3$ & $38 \cdot 0$ & $38 \cdot 3$ & $43 \cdot 7$ & 63.7 & $25 \cdot 7$ & 41.0 \\
\hline 4 & Call & $41 \cdot 2$ & $33 \cdot 2$ & $25 \cdot 5$ & $44 \cdot 8$ & $30 \cdot 8$ & $52 \cdot 0$ & $27 \cdot 0$ & $52 \cdot 6$ & $31 \cdot 2$ & $45 \cdot 7$ \\
\hline 5 & $\mathrm{Zn} \emptyset$ & 65.4 & 66.5 & 51.5 & $70 \cdot 6$ & 54.9 & 93.9 & 63.4 & $84 \cdot 7$ & $58 \cdot 8$ & $79 \cdot 0$ \\
\hline 6 & $\mathrm{Fe}^{\star \star}$ & $37 \cdot 8$ & $28 \cdot 8$ & 31.9 & $32 \cdot 3$ & 23.4 & $35 \cdot 6$ & $37 \cdot 8$ & $46 \cdot 8$ & $32 \cdot 7$ & $36 \cdot 0$ \\
\hline
\end{tabular}

$\mathrm{BL}$, baseline; EL, endline.

* Calculated using PC SIDE, except for Fe (full-probability approach).

† RDA for children aged $12-47$ months was $4184 \mathrm{~kJ}$ (1000 kcal) and for children aged $48-59$ months it was $6485.2 \mathrm{~kJ}(1550 \mathrm{kcal})$, and the cut-off for inadequacy was $<77 \%$ RDA.

¥ RDA for children aged $12-47$ months was $25 \mathrm{~g}$ and for children aged $48-59$ months it was $39 \mathrm{~g}$, and the cut-off for inadequacy was $<77 \%$ RDA.

$\S$ RDA for children aged 12-47 months was 400 retinol equivalents and for children aged $48-59$ months it was 450 retinol equivalents, and the cut-off for inadequacy was the values $<$ RDA divided by conversion factor of 1.4 .

॥ RDA for children aged 12-47 months and 48-59 months was $500 \mathrm{mg}$, and the cut-off for inadequacy was the values $<$ RDA divided by conversion factor of 1.2 .

II RDA for children aged 12-47 months was $8.2 \mathrm{mg}$ and for children aged $48-59$ months it was $9.7 \mathrm{mg}$, and the cut-off for inadequacy was the values <RDA divided by conversion factor of 1.2 .

** RDA for children aged 12-47 months was $8 \mathrm{mg}$ and for children aged $48-59$ months it was $9 \mathrm{mg}$, and the cut-off for inadequacy was calculated using full-probability approach with $10 \%$ bioavailability.

meat was consumed by very few $(<10 \%)$. At endline, significantly more of the children had consumed liquid milk than at baseline ( $44.5 v .32 \cdot 3 \%$, respectively). The consumption of powdered milk significantly increased from baseline to follow-up II, but it decreased significantly at endline (20.4\%), even lower than the value at baseline. This decrease was particularly observed among children aged 24-35 months.

\section{Dietary diversity, animal source food consumption and adequacy of energy and nutrient intake}

The majority of the children consumed adequate energy $(72 \cdot 2 \%)$ and protein $(80 \cdot 2 \%)$ throughout the 1 -year period of observation (Table 4). The adequacy of micronutrient intake was more problematic, with only $35 \cdot 7,14.5$ and $4 \cdot 1 \%$ of the children achieving adequate intake in $\geq 3$ visits of vitamin $\mathrm{A}, \mathrm{Ca}$ and $\mathrm{Zn}$, respectively. During the 1 -year period, the proportion of children with adequate $\mathrm{Ca}$ intake in $\geq 3$ visits was significantly higher in the 'diverse diet in $\geq 3$ visits' group than in the 'diverse diet in $<3$ visits' group $(27 \cdot 3 v .9 \cdot 7 \%$, respectively). The adequate intake of energy and other nutrients, in contrast, was not significantly associated with dietary diversity.

Among the three types of ASF, the consumption of flesh foods was not significantly associated with energy and nutrient adequacy, as examined in this study. The proportion of children with adequate vitamin $\mathrm{A}, \mathrm{Ca}$ and $\mathrm{Zn}$ intake in $\geq 3$ visits was higher among the children who more frequently consumed milk and dairy products than among those with less frequent consumption ( $41.4 v .26 .4 \%$ for vitamin A, $P=0.022 ; 18.6 v$. $8.0 \%$ for $\mathrm{Ca}, P=0.029$; and 37.9 v. $12.6 \%$ for $\mathrm{Zn}, P<0.001)$. The results were similar for frequent egg consumption and protein intake adequacy $(83 \cdot 1 v .65 \cdot 6 \%, P=0.022)$.

\section{Dietary diversity, animal source food consumption, adequacy of energy and nutrient intake and height-for-age z score}

A multiple linear regression analysis was performed to assess the roles of good dietary diversity, ASF consumption and adequacy of energy and nutrient intake on HAZ at endline by controlling for demographic characteristics and baseline HAZ. Table 5 shows that dietary diversity was not significantly associated with the HAZ at endline $(P=0 \cdot 358)$. Similarly, Table 6 indicates that the three types of ASF were not significantly associated with HAZ at endline. The consumption of the grains/cereal and fat/oil groups was not included in the regression analysis, as $>95 \%$ of the children consumed these two food groups across visits. Regarding adequacy, the 
Table 5. Multiple linear regression analysis to explain the influence of dietary diversity on HAZ-score at endline of the children aged 12-59 months (Unstandardised and standardised coefficients with their standard errors)

\begin{tabular}{|c|c|c|c|c|}
\hline & $b$ & SE & $\beta$ & $P$ \\
\hline (Constant) & -0.184 & 0.145 & & 0.205 \\
\hline Maternal education $(0=\leq 6$ years of schooling, $1=7-11$ years of schooling, $2=\geq 12$ years of schooling) & -0.011 & 0.036 & -0.010 & 0.764 \\
\hline Age group at baseline $(0=12-23$ months, $1=24-35$ months, $2=36-47$ months, $3=48-59$ months $)$ & 0.072 & 0.024 & 0.091 & 0.002 \\
\hline Sex $(0=$ male, $1=$ female $)$ & -0.001 & 0.055 & -0.01 & 0.982 \\
\hline Household wealth index tercile ( $0=$ low, $1=$ medium, $2=$ high $)$ & -0.033 & 0.034 & -0.023 & 0.350 \\
\hline HAZ at baseline & 0.954 & 0.030 & 0.925 & 0.000 \\
\hline Dietary diversity category ( $0=$ had diverse diet in $<3$ visits, $1=$ had diverse diet in $\geq 3$ visits) & 0.036 & 0.061 & 0.017 & 0.358 \\
\hline
\end{tabular}

Table 6. Multiple linear regression analysis to explain the influence of animal source foods consumption on HAZ-score at endline of the children aged 12-59 months

(Unstandardised and standardised coefficients with their standard errors)

\begin{tabular}{|c|c|c|c|c|}
\hline & $b$ & SE & $\beta$ & $P$ \\
\hline (Constant) & -0.110 & 0.168 & & 0.514 \\
\hline Maternal education ( $0=\leq 6$ years of schooling, $1=7-11$ years of schooling, $2=\geq 12$ years of schooling) & -0.022 & 0.038 & -0.020 & 0.558 \\
\hline Age group at baseline $(0=12-23$ months, $1=24-35$ months, $2=36-47$ months, $3=48-59$ months $)$ & 0.077 & 0.025 & 0.089 & 0.000 \\
\hline Sex $(0=$ male, $1=$ female $)$ & 0.004 & 0.056 & 0.007 & 0.944 \\
\hline Household wealth index tercile $(0=$ low, $1=$ medium, $2=$ high $)$ & -0.032 & 0.037 & 0.029 & 0.384 \\
\hline HAZ at baseline & 0.946 & 0.032 & 0.923 & 0.000 \\
\hline \multicolumn{5}{|l|}{ Food groups consumption* } \\
\hline Flesh foods & -0.020 & 0.069 & -0.009 & 0.772 \\
\hline Milk and dairy products & 0.030 & 0.059 & 0.015 & 0.315 \\
\hline Eggs & -0.086 & 0.077 & -0.035 & 0.265 \\
\hline Legumes/nuts & 0.048 & 0.056 & 0.025 & 0.398 \\
\hline Vitamin A-rich FVT & -0.019 & 0.057 & -0.010 & 0.737 \\
\hline Other vegetables & -0.057 & 0.057 & -0.029 & 0.317 \\
\hline Other fruits & 0.003 & 0.076 & 0.000 & 0.970 \\
\hline
\end{tabular}

FVT, fruits vegetables tubers.

* $0=$ less frequently consumed (consumed in $<3$ out of the four dietary recalls), $1=$ more frequently consumed (consumed in $\geq 3$ out of four dietary recalls).

adequate intake of energy and nutrients in $\geq 3$ visits was not among the significant predictors of the children's HAZ at endline (data not shown).

\section{Discussion}

The results of this study indicated that more frequent consumption of a diverse diet was not associated with HAZ at endline after controlling for demographic characteristics and baseline HAZ. Similarly, the consumption of diverse food groups was not significantly associated with HAZ at endline. The findings were not in line with previous studies examining the association between dietary diversity and HAZ or stunting. Two national-scale studies among children aged 12-36 months in Ethiopia ${ }^{(24)}$ and

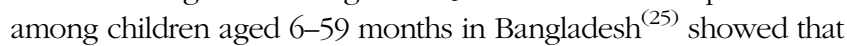
food-group diversity was significantly associated with increased HAZ or reduced stunting. Another analysis of data on multiple countries confirmed the importance of minimum acceptable diet, including dietary diversity, as an independent factor of child growth, including stunting ${ }^{(26)}$.

Nevertheless, a study among 6-42-month-old Senegalese children demonstrated that a 7-day dietary diversity index was not significantly associated with height-for-age after adjusting for the child's age. The association remained non-significant after adjustment for other variables ${ }^{(27)}$.
Comparable studies longitudinally measuring the dietary diversity, nutrient adequacy and linear growth of children are relatively rare. A study in the Philippines showed that dietary diversity's ability to predict nutrient adequacy diminished with increasing age, indicating that nine food groups might not be diverse enough for older children ${ }^{(28)}$. A study among children aged 6-17 months in Madagascar found no significant association between the crosssectional infant and child feeding index at each of three visits, with 3-month intervals and length-for-age $z$-score (LAZ), at the end of the study after adjusting for confounders ${ }^{(29)}$. However, when the longitudinal approach was used (created by summing up the index score over the three visits), it showed that the mean LAZ increased as the scores of the feeding index increased, suggesting that the longitudinal index was a good predictor of child growth.

In terms of dietary diversity, ASF consumption is strongly recommended because its nutrient density increases the likelihood of a child meeting the nutrient requirements ${ }^{(30)}$. A study among Cambodian children aged 12-59 months indicated that consuming a diverse diet, specifically ASF, was significantly associated with a reduction in stunting ${ }^{(31)}$. An analysis using the National Nutrition Surveillance data in Indonesia showed a significant relationship between stunting in 0-59-month-old children and the proportion of household expenditure on ASF in households living in poor urban $\operatorname{areas}^{(32)}$. The risk of stunting was $22 \%$ lower in households, with a higher rather than a lower quintile expenditure of ASF. 
The authors suggested that the higher household expenditure be used as a proxy for higher ASF consumption, but such an association was not apparent in this study.

The non-significant association between feeding practice and linear growth found in the present study, despite the use of a longitudinal approach to better capture the dietary habits, remains unclear. An explanation may be related to the difference in length/height increments across age. The linear growth of older children, particularly those aged >36 months old, is less sensitive to their food consumption ${ }^{(27)}$. Comparing our results with those from the Madagascar study, which used a similar approach, the children in our study were much older. Nevertheless, previous studies have suggested that the significant association included children from various age groups.

As elaborated in previous reviews and studies, a higher dietary diversity may indicate a higher likelihood of meeting daily energy and nutrient requirements that positively influence nutritional status among young children ${ }^{(25,33)}$. The results of the present study demonstrated that frequent consumption of a diverse diet over a 1-year period was significantly associated with adequate intake of $\mathrm{Ca}$.

In addition, the present study also showed that consumption of milk and dairy products was associated with vitamin $\mathrm{A}, \mathrm{Ca}$ and $\mathrm{Zn}$ adequacy. Studies have shown that milk is rich in nutrients, particularly $\mathrm{Zn}$ and good-quality proteins, which makes it a suitable food for supporting growth, particularly among young children ${ }^{(12)}$. In addition, milk intake is related to an increasing level of insulin-like growth factor- $1^{(34)}$. There was a proposal that a diet containing $25-33 \%$ protein from milk would significantly improve the nutritional status of moderately malnourished children, and $50 \mathrm{~g}$ powdered milk provides about $36-56 \%$ of protein requirements ${ }^{(35)}$.

Of particular importance is the fact that the proportion of children who consumed milk and dairy products was high. Liquid milk in a ready-to-drink package $(125-250 \mathrm{ml})$ is a favourite snack among children, as it is readily available for purchase from many vendors in the study area. In Indonesia, most of the milk available is fortified with various micronutrients depending on the brand and the categories within each brand. On the basis of the most frequently consumed brand of milk in this study, $20 \mathrm{~g}$ of powdered milk contains approximately $120 \mu \mathrm{g}$ of vitamin A, $288 \mathrm{mg}$ of $\mathrm{Ca}$, $2.1 \mathrm{mg}$ of $\mathrm{Fe}$ and $9.5 \mathrm{mg}$ of $\mathrm{Zn}$, whereas $125 \mathrm{ml}$ of liquid milk contains $75 \mu \mathrm{g}$ of vitamin $\mathrm{A}, 100 \mathrm{mg}$ of $\mathrm{Ca}, 0.6 \mathrm{mg}$ of $\mathrm{Fe}$ and $0.5 \mathrm{mg}$ of $\mathrm{Zn}$.

Eggs - another type of ASF frequently consumed by the children in the present study - were significantly associated with adequate protein intake. Eggs were generally cheaper, easy to prepare and preferred by the children. A recent review highlighted eggs' potential to increase dietary diversity and nutrient intake ${ }^{(36)}$. In the current study, the consistent consumption of eggs over the 1-year study period was associated with consistent adequate intake of protein. Other types of ASF, that is, poultry/fish/meat, were not significantly associated with energy and nutrient adequacy. Poultry contains a protein similar to that found in red meat, but only about half the Fe and Zn. In this study, meat was most commonly consumed in the form of relatively cheap processed meats (such as sausage, nuggets and meatballs) that were readily available in convenience stores and from street food vendors. However, the nutrient content of processed meats varies depending on quality and price. The proportion of children who consumed non-processed meats was very low ( $6.5 \%$ on average across the four visits).

Micronutrient ( $\mathrm{Zn}, \mathrm{Fe}$ and $\mathrm{Ca}$ ) intake inadequacies were very prevalent across all of the age groups. Nevertheless, the magnitude of inadequate energy, protein and micronutrient intake in this study was lower than that found in an earlier study in Indonesia ${ }^{(5)}$. The difference might lie in the different approach used to estimate nutrient intake inadequacies. We used an approach that measured the 'usual' intake based on two repeated 24-h recalls. The approach better estimated the prevalence of inadequate intake of nutrients at the population level, compared with the classical method of calculating the percentage of children with a nutrient intake below the $\mathrm{RDA}^{(37)}$

The proportion of children with an inadequate intake of vitamin A was lowest among those aged 12-23 months, possibly affected by breastmilk intake. Assuming that the children had moderate breastmilk intake (about $500 \mathrm{ml}$ of breastmilk/d), the vitamin A intake from the breastmilk would be approximately $345 \mu \mathrm{g}^{(22)}$. Because the breastmilk intake decreased as the children aged, the proportion of vitamin A intake inadequacy increased, and among older children the higher proportion consuming flesh foods and milk and dairy products could not circumvent the inadequate vitamin A intake. This situation was worsened by the decreasing proportion of children consuming vitamin A-rich fruit and vegetables.

The high proportion of inadequate intake of $\mathrm{Zn}$ was in line with a recent review showing that Indonesia has a high prevalence of Zn deficiency ( $>25 \%$ ), using food balance sheet supply data as the basis for the estimation ${ }^{(38)}$. The review also demonstrated that the contribution of $\mathrm{Zn}$ from ASF was negatively correlated with the estimated prevalence of inadequate $\mathrm{Zn}$ intake. In countries with a high prevalence of $\mathrm{Zn}$ intake inadequacy, about $12 \%$ of the dietary $\mathrm{Zn}$ was obtained from ASF, compared with $51.2 \%$ in countries with low prevalence of $\mathrm{Zn}$ intake inadequacy. Despite a high prevalence of ASF consumption, this study showed a high prevalence of $\mathrm{Zn}$ intake inadequacy, indicating that the ASF consumption was not adequate in quality and/or quantity.

In general, the proportion of inadequate micronutrient intake was higher at endline than at baseline and across age groups. The higher proportion of inadequate micronutrient intake at endline signified that as the children got older it was more difficult to fulfil the micronutrient requirements. Despite a significantly higher proportion of children who consumed milk and dairy products at endline than at baseline, the increased proportion was mainly because of an increased consumption of liquids with lower nutrient content than powdered milk (the consumption of which was significantly lower at endline than at baseline). The decreased intake of breastmilk and powdered milk (as important contributors of micronutrients) at endline might also explain the observed increase in stunting prevalence at endline (from $45.6 \%$ at baseline to $50.0 \%$ at endline). The increased prevalence, however, was not significant.

Despite high ASF consumption, only approx $50 \%$ of the children had high dietary diversity. The overall dietary diversity 
was steady within the 1-year observation period across age groups. The consumption of flesh foods (including processed meats) and milk/dairy products significantly increased across the four visits, whereas the consumption of vitamin A-rich fruits and vegetables unexpectedly decreased. Fruit and vegetables are an important source of vitamins and minerals, particularly among children with limited access to ASF. In addition, they are also an important source of dietary fibre.

This study examined the dynamics of food consumption, particularly in regard to dietary diversity and ASF; however, a trend was not apparent. Thus, a more refined dietary diversity indicator might be needed, such as measurements that include the quantity (amount) and quality (diversity) of food consumption. Although the sample size was adequate to detect changes in length increments across the 1-year observation period, it was not adequate to capture the changes in dietary diversity patterns or food consumption.

In conclusion, the consumption of diverse diets and ASF was not a significant predictor of HAZ among children aged 12-59 months. However, the consumption of diverse diets was significantly associated with $\mathrm{Ca}$ intake adequacy. Regarding food groups, ASF consumption was significantly associated with adequate intake of protein and micronutrients, particularly vitamin $\mathrm{A}, \mathrm{Ca}$ and $\mathrm{Zn}$. Thus, our findings do not discontinue the communication on the benefits of diverse diet, including ASF, in supporting the linear growth of young children.

\section{Acknowledgements}

The authors thank Lina Marlina for field establishment and Abas Basuni Jahari for statistical analysis assistance.

This study was supported by PT Sari Husada Generasi Mahardhika and PT Nutricia Indonesia Sejahtera (grant number: 172/Legal/SH-SEAMEO/XII/10). Both authors report grants from PT Sari Husada Generasi Mahardhika and PT Nutricia Indonesia Sejahtera during the study. The donors had no role in the study design, analysis or the writing of this article.

Both authors were involved in the concept and design of the study, data collection, data analysis, interpretation of results, manuscript writing and approval. There were no conflicts of interest.

\section{References}

1. Ministry of Health (2007) Basic Health Survey (Riset Kesehatan Dasar/RISKESDAS) 2007. Jakarta: MoH Jakarta.

2. Bhutta ZA, Das JK, Rizvi A, et al. (2013) Evidence-based interventions for improvement of maternal and child nutrition: what can be done and at what cost? Lancet 382, 452-477.

3. Hautvast JL, van der Heijden LJ, Luneta AK, et al. (1999) Food consumption of young stunted and non-stunted children in rural Zambia. Eur J Clin Nutr 53, 50-59.

4. Stewart C, Iannotti L, Dewey KG, et al. (2013) Contextualising complementary feeding in a broader framework for stunting prevention. Matern Child Nutr 9, Suppl. 2, 27-45.

5. Sandjaja S, Budiman B, Harahap H, et al. (2013) Food consumption and nutritional and biochemical status of 0.5-12year-old Indonesian children: the SEANUTS study. Br J Nutr 110, Suppl. 3, S11-S20.
6. Swindale A \& Bilinsky P (2006) Household Dietary Diversity Score (HDDS) for measurement of household food access: indicator guide. http://www.fantaproject.org/monitoring-and-evaluation/ household-dietary-diversity-score (accessed November 2014).

7. Steyn NP, Nel JH, Nantel G, et al. (2006) Food variety and dietary diversity scores in children: are they good indicators of dietary adequacy? Public Health Nutr 9, 644-650.

8. Kennedy GL, Pedro MR, Seghieri C, et al. (2007) Dietary diversity score is a useful indicator of micronutrient intake in non-breast-feeding Filipino children. J Nutr 137, 472-477.

9. Kennedy G, Ballard T \& Dop MC (2007) Guidelines for Measuring Household and Individual Dietary Diversity. Rome: FAO

10. Neumann CG, Bwibo NO, Murphy SP, et al. (2003) Animal source foods improve dietary quality, micronutrient status, growth and cognitive function in Kenyan school children: background, study design and baseline findings. J Nutr 133, 3941S-3949S.

11. Murphy S \& Allen LH (2003) Nutritional importance of animal source foods. J Nutr 133, Suppl., 3932S-3935S.

12. Michaelsen KF, Hoppe C, Roos N, et al. (2009) Choice of foods and ingredients for moderately malnourished children 6 months to 5 years of age. Food Nutr Bull 30, Suppl., S343-S404.

13. Grillenberger M, Neumann CG, Murphy SP, et al. (2006) Intake of micronutrients high in animal-source foods is associated with better growth in rural Kenyan school children. $\mathrm{BrJ}$ Nutr 95, 379-390.

14. Neumann C, Harris DM \& Rogers LM (2002) Contribution of animal source foods in improving diet quality and function in children in the developing world. Nutr Res 22, 193-220.

15. BPS, National Family Planning Coordinating Board, Ministry of Health, et al (2012) Indonesia Demographic and Health Survey 2012. Calverton, MD: BPS and ORC Macro.

16. Whitley E \& Ball J (2002) Statistic Review 4: Sample Size Calculation. Critical Care 6, 335-341.

17. Gibson RS (2005) Principles of Nutritional Assessment. New York: Oxford University Press.

18. Hatløy A, Torheim LE \& Oshaug A (1998) Food variety - a good indicator of nutritional adequacy of the diet? A case study from an urban area in Mali, West Africa. Eur J Clin Nutr 52, 891-898.

19. Indonesian Institute of Sciences (LIPI) (2004) Angka kecukupan gizi yang dianjurkan dan label gizi (Recommended dietary allowances and food labeling). In WidyakaryaPangandanGizi (National Workshop of Food and Nutrition). Jakarta: Indonesian Institute of Sciences/LIPI

20. World Health Organization \& Food and Agricultural Organization (2006) Defining and setting programme goals. In Guidelines on Food Fortification with Micronutrients, pp. 139-177 [L Allen, $\mathrm{B}$ de Benoist, O Dary and R Hurrell, editors]. Geneva: WHO.

21. Gibson RS \& Ferguson EL (2008) An Interactive 24-hour Recall for Assessing the Adequacy of Iron and Zinc Intakes in Developing Countries. HarvestPlus Technical Monograph 8. Washington, DC: International Food Policy Research Institute (IFPRI) and International Centre for Tropical Agriculture (CIAT).

22. World Health Organization \& United Nations International Children's Emergency Fund (1998) Complementary Feeding of Young Children in Developing Countries: A Review of Current Scientific Knowledge. Geneva: WHO.

23. Ministry of Health (2004) Tabel Angka Kecukupan Gizi 2004 bagi Orang Indonesia (Recommended Nutrient Intakes for Indonesians 2004). http://gizi.depkes.go.id/download/ AKG2004.pdf (accessed October 2013).

24. Arimond M \& Ruel MT (2002) Summary indicators for infant and child feeding practices: an example from the Ethiopia demographic and health survey 2000. Food consumption and 
nutrition division discussion paper. Washington, DC: International Food Policy Research Institute.

25. Rah JH, Akhter N, Semba RD, et al. (2010) Low dietary diversity is a predictor of child stunting in rural Bangladesh. Eur J Clin Nutr 64, 1393-1398.

26. Marriott BP, White A, Hadden L, et al. (2012) World Health Organization (WHO) infant and young child feeding indicators: associations with growth measures in 14 low-income countries. Matern Child Nutr 8, 354-370.

27. Ntab B, Simondon KB, Milet J, et al. (2005) A young child feeding index is not associated with either height-for-age or height velocity in rural Senegalese children. J Nutr $\mathbf{1 3 5}$, 457-464.

28. Eckhardt CL, Suchindran C, Gordon-Larsen P, et al. (2005) The association between diet and height in the postinfancy period changes with age and socioeconomic status in Filipino youths. J Nutr 135, 2192-2198.

29. Moursi M, Martin-Prevel Y, Eymard-Duvernay S, et al. (2008) Assessment of child feeding practices using a summary index: stability over time and association with child growth in urban Madagascar. Am J Clin Nutr 87, 1472-1479.

30. World Health Organization (2007) Indicators for Assessing Infant and Young Child Feeding Practices. Part 1: Definitions. Geneva: WHO.
31. Darapheak C, Takano T, Kizuki M, et al. (2013) Consumption of animal source foods and dietary diversity reduce stunting in children in Cambodia. Int Arch Med 6, 29.

32. Sari M, de Pee S, Bloem MW, et al. (2010) Higher household expenditure on animal-source and nongrain foods lowers the risk of stunting among children 0-59 months old in Indonesia: implications of rising food prices. J Nutr 140, 195S-200S.

33. Arimond M \& Ruel MT (2004) Dietary diversity is associated with child nutritional status: evidence from 11 demographic and health surveys. J Nutr 134, 2579-2585.

34. Hoppe C, Mølgaard C \& Michaelsen KF (2006) Cow's milk and linear growth in industrialized and developing countries. Annu Rev Nutr 26, 131-173.

35. Golden MH (2009) Proposed recommended nutrient densities for moderately malnourished children. Food Nutr Bull 30, Suppl., S267-S342.

36. Iannotti LL, Lutter CK, Bunn DA, et al. (2014) Eggs: the uncracked potential for improving maternal and young child nutrition among the world's poor. Nutr Rev 72, 355-368.

37. Carriquiry AL (1999) Assessing the prevalence of nutrient inadequacy. Public Health Nutr 2, 23-33.

38. Wessells KR \& Brown KH (2012) Estimating the global prevalence of zinc deficiency: results based on zinc availability in national food supplies and the prevalence of stunting. PLOS ONE 7, e50568. 